\title{
Análise da Qualidade do Serviço: um estudo entre a percepção do cliente e do guia em roteiros regionais do SESC - Santa Catarina, Brasil
}

\author{
Maria Helena Alemany Soares ${ }^{a}$ \\ Carlos Marcelo Ardigób \\ Marcos Estevão Santiago de Melo Filho ${ }^{c}$
}

\section{Resumo}

Para atender a demanda da atividade turística e garantir a excelência no serviço, o mercado de trabalho tem exigido uma mão de obra qualificada e inovadora. Tendo em vista essa necessidade, o objetivo deste trabalho foi analisar a qualidade percebida pelos clientes em relação aos serviços prestados pelos guias de turismo, em roteiros regionais do SESC - SC por meio de inferências estatísticas. Questionários foram aplicados a clientes e guias de turismo, resultando em uma amostragem de 180 casos com o primeiro grupo e de 09 casos com o segundo. 0 delineamento metodológico da pesquisa se caracteriza como científico, de abordagem quantitativa, de natureza aplicada e descritiva. Os procedimentos técnicos utilizados foram a pesquisa bibliográfica, seguida de um survey, estabelecida segundo o modelo SERVPERF. Por meio de análise estatística foi possível verificar que a prestação do serviço oferecido por este profissional resulta em satisfação com a qualidade de serviço, e que a percepção de cliente e guia são relativamente semelhantes, indicando inexistência de lacunas (gaps) entre as percepções.

Palavras-chave: Turismo; Guia de Turismo; Qualidade de serviço; Satisfação dos clientes.

\section{Abstract \\ Analysis of the Quality Service: a study between the customer and the tour guide perceptions on regional tours of SESC-Santa Catarina, Brasil}

To meet the demand of tourism and ensure excellence in service, the labor market has required a skilled and innovative workforce. In view of this need the objective of this work was to analyze the quality perceived by the clients in relation to the services provided by the tour guides, in SESC - SC regional itineraries through statistical inferences. Questionnaires were applied to clients and tour guides, resulting in a sampling of 180 cases with the first group and 09 cases with the second. The methodological design of the research is characterized as scientific, with a quantitative approach, of an applied and descriptive nature. The technical procedures used were the bibliographic research,

a. Docente do Instituto Federal de Santa Catarina (IFSC), Campus Florianópolis Continente. Florianópolis, Santa Catrarina, Brasil. Mestre no Programa de Pós-graduação em Turismo e Hotelaria (PPGTH) da Universidade do Vale do Itajaí- UNIVALI. Balneário Camboriú, Santa Catarina, Brasil. E-mail: helenaalemany52@gmail.com

b. Doutor pelo Programa de Pós-Graduação em Engenharia de Produção (PPGEP) da Universidade Federal de Santa Catarina (UFSC), Florianópolis, Santa Catarina, Brasil. Docente do Programa de Pós-graduação em Turismo e Hotelaria (PPGTH) e do Programa de Mestrado Profissional em Gestão, Internacionalização e Logística (PMPGIL) da da Universidade do Vale do Itajaí- UNIVALI. Itajaí, Santa Catarina, Brasil. marcelo.ardigo@univali.br

c. Doutor em Engenharia Química pela Universidade Federal de Santa Catarina (UFSC), Florianópolis, Santa Catarina, Brasil. E-mail: santiagodemelo.marcos@gmail.com 
followed by a survey, established according to the SERVPERF model. Through statistical analysis it was possible to verify that the service provided by this professional results in satisfaction with the quality of service, as well as the customer perception and guide are relatively similar, indicating absence of gaps between perceptions

Keywords: Tourism; Tour Guide; Quality of service; Customer satisfaction.

\section{Resumen}

Análisis de la calidad del servicio: un estudio entre la percepción del cliente y el guía en rutas regionales de SESC-Santa Catarina, Brasil

Para satisfacer la demanda de la actividad turística y garantizar la excelencia en el servicio, el mercado de trabajo ha requrido una mano de obra calificada e innovadora. En vista de esta necesidad, el objetivo de este trabajo fue analizar la calidad percibida por los clientes en relación a los servicios prestados por guías de turismo, en rutas regionales de SESC-SC por medio de inferencias estadísticas. Se aplicaron cuestionarios a los clientes y guías de turismo, resultando en 180 casos de muestra con el primer grupo y 09 casos con el segundo. La delineación metodológica de la investigación se caracteriza como aproximación científica, cuantitativa de carácter aplicado y descriptivo. Los procedimientos técnicos utilizados fueron la literatura, seguido de una survey, establecida según el modelo SERVPERF. A través del análisis estadístico fue posible verificar que el servicio brindado por este profesional resulta en satisfacción con la calidad del servicio, y que la percepción del guía y del cliente son relativamente similares, lo que indica la ausencia de brechas entre las percepciones.

Palabras clave: Turismo; Guía de turismo; Calidad del servicio; Satisfacción del cliente.

\section{INTRODUÇÃo}

O Brasil em sua dimensão continental, apresenta ampla diversidade étnica, cultural, paisagística e humana, que despertam o interesse de um número cada vez maior de pessoas que, em parte de seu tempo livre, buscam conhecer e vivenciar múltiplas experiências. Atendendo a essa demanda real e latente, almeja-se concretizar o desejo pessoal do consumidor que utiliza a fruição material e subjetiva para a escolha do destino turístico (BENI, 2006).

Nesse contexto, e com um nível de clientes cada vez mais exigentes, essa situação requer mais atenção à qualidade dos serviços. Denota-se assim, que a gestão da qualidade como estratégia competitiva é um requisito necessário para o setor turístico e um diferencial na prestação dos serviços. Paladini (1998) aponta a necessidade do comprometimento de todos os seus colaboradores no organograma de uma empresa, para que a gestão da qualidade se desenvolva de forma progressiva. Silva (2006) também menciona que o conceito de qualidade total não é estático, devendo atualizar-se para acompanhar as mudanças perante as necessidades e as preferências dos clientes.

Explanam Sarmento e Costa (2011), que a percepção não é devida somente a uma resposta aos sentidos e aos estímulos externos, mas também uma atividade crítica. Todavia, Téboul (1999) menciona que a melhor forma de conhecer a percepção do cliente quanto qualidade do serviço percebido é quantificar o desempenho do serviço, de modo a tornar a percepção intangível em tangível.

Desse modo, nas atividades programadas, introduz-se a presença do guia de turismo, importante agente no exercício diário da atividade turística, e que de- 
verá apresentar competências e habilidades profissionais, características para a segurança e a satisfação dos clientes. 0 guia é o elemento humano, o intérprete e o executor do roteiro e da programação (técnica, artística, sociocultural e patrimonial) dos destinos ofertados pelas agências de turismo (CANANI, 1999). Mais que informar, o guia de turismo deve prestar um atendimento de qualidade para a garantia da segurança e a satisfação do cliente, estabelecendo o elo entre quem consome e quem oferta a experiência turística (GONZALEZ; MARTINEZ, 2010).

0 guia de turismo contemporâneo tem um papel plurifacetado que consiste em várias sub funções distintas e complexas (RABOTÍC, 2010). El-Sharkawy (2015) observa que o guia de turismo possui o papel de motivador do turista, bem como a responsabilidade de promover um ambiente receptivo e acolhedor, disponibilizando informações suficientes para atender bem o cliente.

No intuito de avaliar a satisfação do cliente e a qualidade percebida por ele, o artigo apresenta a aplicação do modelo de avaliação da qualidade de serviços SERVPERF (Cronin \& Taylor, 1992), fundamentado no modelo SERVQUAL (Parasuraman et al, 1985). A concepção deste propósito se deu por meio da avaliação da percepção dos clientes quanto à qualidade da prestação dos serviços dos Guias de Turismo; da percepção dos Guias de Turismo quanto ao serviço prestado; e a comparação dessas percepções (dos clientes e dos Guias de Turismo), considerando as possíveis lacunas (gaps) existentes na qualidade do serviço analisado.

O estudo considerou o turismo doméstico, tendo como foco o promovido pelo Departamento Nacional do Serviço Social do Comércio (SESC), cuja abrangência de atuação se estende por todo o território nacional. Composto por Departamentos Regionais (DR), dentre eles a unidade do SESC Prainha, em Florianópolis, Santa Catarina, que oferece uma variada gama de serviços na área da educação, saúde, cultura, lazer e, ainda, o Turismo Social.

Assim, neste artigo foi considerado "cliente", o turista/excursionista na modalidade do turismo emissivo oferecido pelo SESC e o serviço prestado pelo guia dentro da unidade federativa de Santa Catarina. Contudo, é importante salientar que a atividade do guia ocorre, em grande parte, nos deslocamentos, nos destinos e atrativos visitados, os quais passam a se integrar ao serviço prestado pelo profissional.

Considerando esta conjuntura de análise, na sequência, na seção de revisão de literatura discute-se inicialmente o turismo social, o guia de turismo, a qualidade dos serviços no turismo e o modelo SERVPERF. Posteriormente, apresenta-se o delineamento metodológico para em seguida, apresentar os resultados do estudo, bem como as conclusões surgidas a partir destes..

\section{TURISMO SOCIAL}

O Turismo Social enquanto modalidade comercial, isto é, envolvendo negócios turísticos (pacotes, hospedagem, alimentação) já é uma realidade exercida por parte dos consumidores de baixa renda. Mas, diferentemente de como ocorre na maioria dos países da Europa e América Latina, no Brasil, as iniciativas desenvolvidas pelos órgãos públicos ainda são incipientes, restritas a algumas instituições voltadas para o bem-estar social, dentre as quais destaca-se o Serviço Social do Comércio (SESC). (FALCÃO, 2006). 
Em termos de América do Sul, Abítia (2006, p. 151), menciona que "geralmente não existe oferta suficiente para os públicos de nosso interesse que incluam aspectos sociais. Tampouco instrumentos efetivos de apoio a esses públicos". Ressalta, todavia, a importância do papel das associações, embora sejam escassas as empresas privadas que compartilham dos compromissos ou dos princípios do turismo social. Nessa linha, Beni (2006) menciona que somente com a intervenção do Estado, sem objetivos de lucro e recuperação de investimentos - política, essa, inexistente no Brasil - é que as classes populares serão atendidas na prática do turismo.

O SESC - Serviço Social do Comércio, pioneiro no desenvolvimento do Turismo Social no país, criado em 1946 pelos empresários do comércio, "é uma entidade sem fins lucrativos que desenvolve atividades relacionadas ao bem-estar dos comerciários e de seus dependentes" (SESC, 2007).

Inclui-se nessas atividades a oferta de serviços que proporcionam a experiência do turismo aos seus associados. Desenvolvido dentro dos Departamentos Regionais, o turismo emissivo é a principal modalidade do Turismo Social do SESC. Isso ocorre ao programar para os comerciários e seus familiares, passeios e excursões para as diversas regiões no estado e demais regiões turísticas do país, e que, por meio de preços acessíveis, busca a democratização do acesso ao movimento turístico. Prioritariamente, visa às pessoas de menor renda, de todas as faixas etárias, tanto do público comerciário como não comerciário, com adoção de preços diferenciados, desde que a oferta não venha a prejudicar sua demanda interna (SESC, 2007).

Essa conotação vai ao encontro do mencionado por Falcão (2006, p. 2), que relata que os "valores do turismo social se expressam através de tarifas acessíveis, animação, encontros culturais, dimensão solidária e participativa, atividades educativas e do desenvolvimento das comunidades".

O SESC segue o conceito do Bureau Internacional Tourisme Social - BITS, hoje denominada OITS Organização Internacional de Turismo Social (OITS), para definir as diretrizes para seu programa de Turismo Social. Criada em 1963 e vinculada a Organização Mundial de Turismo, é uma organização que engloba instituições e organismos privados independentes que exercem atividades no desenvolvimento do turismo social (CADERNOS SESC, 2011).

O BITS, menciona que Turismo Social é o "conjunto de relações e fenômenos resultantes da participação no turismo das camadas sociais menos favorecidas, participação esta que se torna possível ou facilitada por medidas de caráter social bem definidas, mas que implicam um predomínio da ideia de serviço e não de lucro" (BITS, 1996, s/p).

Corrobora o Código Mundial de Ética do Turismo (UNWTO, 1999, p.12), no seu artigo 70 - Direito ao Turismo quando dispõe que: o "Turismo Social nomeadamente o turismo associativo, que permite o acesso do maior número de cidadãos aos tempos livres, às viagens e às férias, deve ser desenvolvido com o apoio das autoridades públicas".

Nas atividades programadas dos passeios ou excursões, surge invariavelmente a figura do Guia de Turismo, que executa todo o roteiro e a programação prevista na viagem em contato direto com os clientes. A seguir, uma breve apresentação do Guia de Turismo, profissional que cumpre importante papel no sistema turístico. 


\section{GUIA DE TURISMO}

De acordo com a Federação Mundial das Associações dos Guias de Turismo, o guia de turismo é "a pessoa que orienta os visitantes na língua da sua escolha e interpreta o patrimônio cultural e natural de uma área, e que normalmente possui uma qualificação específica geralmente emitidos e/ou reconhecida pela autoridade competente" (WORLD FEDERATION OF TOURIST GUIDES ASSOCIATION, 2003).

O guia deve ser compreensivo, demonstrar competências comportamentais, cognitivas e afetivas, ser sensível a necessidade dos outros e não fazer julgamentos para assim, aumentar a satisfação dos visitantes (FOWLER; WEERAKIT, 2013). Ele é o protagonista de um processo complexo e, por vezes, representa o elemento determinante para fazer a diferença entre uma viagem bem-sucedida ou o contrário (NASCIMENTO et al, 2014).

A literatura turística tem reconhecido amplamente que "a qualidade do serviço do guia de turismo é um fator crítico para alcançar a satisfação do turista influenciando a reputação da operadora de viagens, a publicidade boca a boca, e afetando a imagem e intenção de revisitar um destino" (CHANG et al. 2010, p. 205). Além da complexidade da atuação do guia na oferta da experiência turística ser ampla, envolvendo além dele, os participantes (turistas) e o meio ambiente (cenário), a oferta ocorre quando todos os três interagem ao mesmo tempo e espaço (RABOTíC, 2010).

Estabelecendo uma relação com a gestão de serviços a partir de Zeithaml e Bitner (2003), é necessário ter habilidades específicas para que as competências do profissional atinjam a qualidade necessária. Assim, conforme já apontava Mossberg (1995), o guia de turismo com a eficiência das informações e conhecimentos, contribui para alcançar uma experiência turística segura, influenciando na qualidade total. A qualidade nos serviços no turismo é abordada a seguir.

\section{QUALIDADE DOS SERVIÇOS EM TURISMO}

Para se compreender a qualidade de serviços em turismo é necessário revisar o conceito de qualidade de serviços, e entender que esse está relacionado a satisfação do cliente. "A literatura aponta diferentes abordagens em relação à satisfação, sendo classificadas como um resultado objetivo, um processo ou um fenômeno psicológico" (SALOMI; MIGUEL, 2002, p. 2).

A satisfação é como um estado cognitivo de ser, adequadamente ou inadequadamente, recompensado (HOWARD; SHETH, 1969). Oliver (1980) entende a satisfação dos clientes como o resultado de uma comparação entre uma expectativa prévia de consumo de produto ou serviço e o resultado da experiência efetiva de consumo. Para Churchill e Suprenant (1982), a satisfação do cliente pode ser compreendida naquilo que resulta da comparação entre o que se recebe e os custos envolvidos na compra, antecipados por ele.

No campo do turismo, o conceito de satisfação do turista segundo EL-Sharkawy (2015, p. 81) é definido como "a qualidade da experiência dos visitantes e o resultado psicológico derivada da interação com diferentes facetas de serviços em um destino". Complementando essa percepção, destaca-se o estudo sobre as 
agências de turismo organizados por Lezana e Vasconcelos (2014, p. 497) que concluem que "a qualidade dos serviços é um elemento importante para o desenvolvimento do setor, na intermediação entre o turista e o destino turístico".

Cano et al. (2012), por meio de ferramentas de gestão e utilizando de indicadores para a análise da satisfação do cliente, verificaram oportunidades para o setor dos guias de turismo, no intuito de ter funcionários mais produtivos com conhecimento geral, assegurar competências, habilidades técnicas e promover atitudes positivas. Brenner (2013) apresenta amplo estudo sobre a motivação do turista até a sua satisfação, definindo esta última como resultado da necessidade prévia e a experiência adquirida, ligando expectativa com resultado positivo em satisfação. Desse modo, a capacidade de adaptação do turista se revela um elemento necessário.

Por conseguinte, em virtude da ocorrência do tempo real do encontro entre a produção e o consumo simultâneo, definido por Zeithaml e Bitner (2003, p. 37) como inseparabilidade ou simultaneidade, é que, "a qualidade dos serviços e a satisfação dos clientes dependerão em grande medida das ações dos funcionários e das interações entre estes e os clientes.

Segundo Lezana e Vasconcelos (2014, p. 498), "deve-se medir a qualidade do serviço por meio de dimensões tangíveis e mensuráveis, focadas na gestão do negócio tais como as relacionadas à infraestrutura, recursos humanos, operações, relacionamento com clientes, entre outras". Parasuraman e Berry (1995) já reforçavam sobre essa necessidade, porém destacando a indispensabilidade de realizá-la constantemente, relatando que isto é uma boa medida para perceber rapidamente os pontos fracos do serviço e eliminá-los.

Essa avaliação neste estudo ocorreu por meio da escala SERVPERF, considerando a investigação das cinco determinantes em que a qualidade dos serviços do Guia de Turismo pode ser percebida: confiabilidade, receptividade, segurança, tangibilidade e empatia. 0 modelo é discutido a seguir.

\section{MODELO SERVPERF}

Os autores Parasuraman, Zeithaml e Berry (1985) após alguns anos de pesquisas e a definição das dimensões da qualidade em serviços, criaram uma escala denominada Service Quality Gap Analysis (SERVQUAL), levando em conta as expectativas dos clientes sobre um determinado serviço relacionando com a percepção de qualidade do serviço recebido.

Esse modelo é constituído por 22 itens que compõem as cinco dimensões ou determinantes da qualidade, apresentadas pelos autores: confiabilidade, receptividade, segurança (competência, cortesia, credibilidade e segurança), tangibilidade e empatia (acesso, comunicação e entendimento do cliente).

Cronin e Taylor (1992) propuseram posteriormente o modelo SERVPERF, que utiliza as mesmas cinco dimensões da qualidade em serviço e as vinte e duas afirmações referentes às percepções sobre o desempenho diretamente do modelo SERVQUAL propostos por Parasuraman, Zeithaml e Berry (1988), suprimindo o parâmetro da expectativa, o qual é dotado de outras 22 questões restantes (CAMISÓN, 2006). 
O SERVPERF não mensura as expectativas dos clientes pois, segundo seus proponentes, a qualidade de serviço é bem melhor avaliada se somente considerar-se as percepções que os consumidores têm a respeito do desempenho do serviço; a avaliação da performance por si só oferece resultados mais adequados na mensuração do construto (CRONIN; TAYLOR, 1992).

O score no modelo SERVPERF é obtido diretamente dos itens de avaliação da performance da escala SERVQUAL, por meio de uma escala de Likert, de cinco ou sete pontos (MARCHETTI; PRADO 2001).

Cronin e Taylor (1992) e Fujii et al (2010) afirmaram também, que a qualidade percebida dos serviços precede a satisfação do cliente, e que essa satisfação tem efeito importante nas intenções de compra. Para os autores, a qualidade de serviço representa-se como: Qualidade de Serviço igual a Performance de Serviço Percebido. Além disso, "a qualidade dos serviços tem uma menor influência nas intenções de compra que a satisfação do cliente, de modo que o resultado (desempenho representado pela satisfação) é o que realmente interessa". (FUJII, et al 2010, p. 9). Cronin e Taylor (1992), em seu artigo constatam que a literatura de marketing (CARMAN, 1990; CHURCHILL; SURPRENANT, 1982), oferece um apoio considerável para a superioridade das medidas baseadas apenas no desempenho de qualidade de serviço sendo, portanto, dispensável apontar as expectativas.

Com base nesse arcabouço conceitual e modelo de mensuração da qualidade, o delineamento metodológico do estudo é descrito na sequência.

\section{DELINEAMENTO METODOLÓGICO}

\section{Lócus da pesquisa}

O escopo de investigação foi estabelecido entre os clientes que utilizam os serviços especificamente turistas/excursionistas, que adquiriram os passeios ou excursões oferecidas pelo SESC - SC na categoria de Turismo Social com saídas da unidade Prainha, Florianópolis. Com base nesse lócus, faz-se necessário uma breve descrição do Estado de Santa Catarina considerando a apresentação estabelecida pela Secretaria de Turismo de Santa Catarina (SANTUR), responsável oficial pela política de gestão do turismo estadual. 0 estado localizado na região sul do Brasil, recebe anualmente cerca de 5 milhões de visitantes, incluindo estrangeiros, brasileiros de outros estados e os próprios catarinenses que circulam pelo território com motivação turística gerando uma renda que representa $12,5 \%$ do Produto Interno Bruto do estado. 0 comércio interno chama atenção pela receita com um mercado consumidor de grande potencial, com arrecadação que representa a $6^{\underline{a}}$ maior receita do país. 0 setor de serviços representa a $7^{a} \underline{a}$ maior receita do país, com destaque para os serviços ligados a transporte e tecnologia. (SANTUR, 2016).

O estado está dividido em doze regiões turísticas (Figura 1), entre elas: Caminho dos Canyons; Caminho dos Príncipes; Caminhos da Fronteira; Caminhos do Alto Vale; Costa Verde \& Mar; Encantos do Sul; Grande Florianópolis; Grande Oeste; Serra Catarinense; Vale das Águas; Vale do Contestado; e Vale Europeu. 
Figura 1: 12 Regiões turísticas do estado de Santa Catarina, Brasil.

Fonte: Adaptado da SOL - Secretaria de Estado de turismo, cultura e esporte de SC (2017).

\section{Coleta de dados}

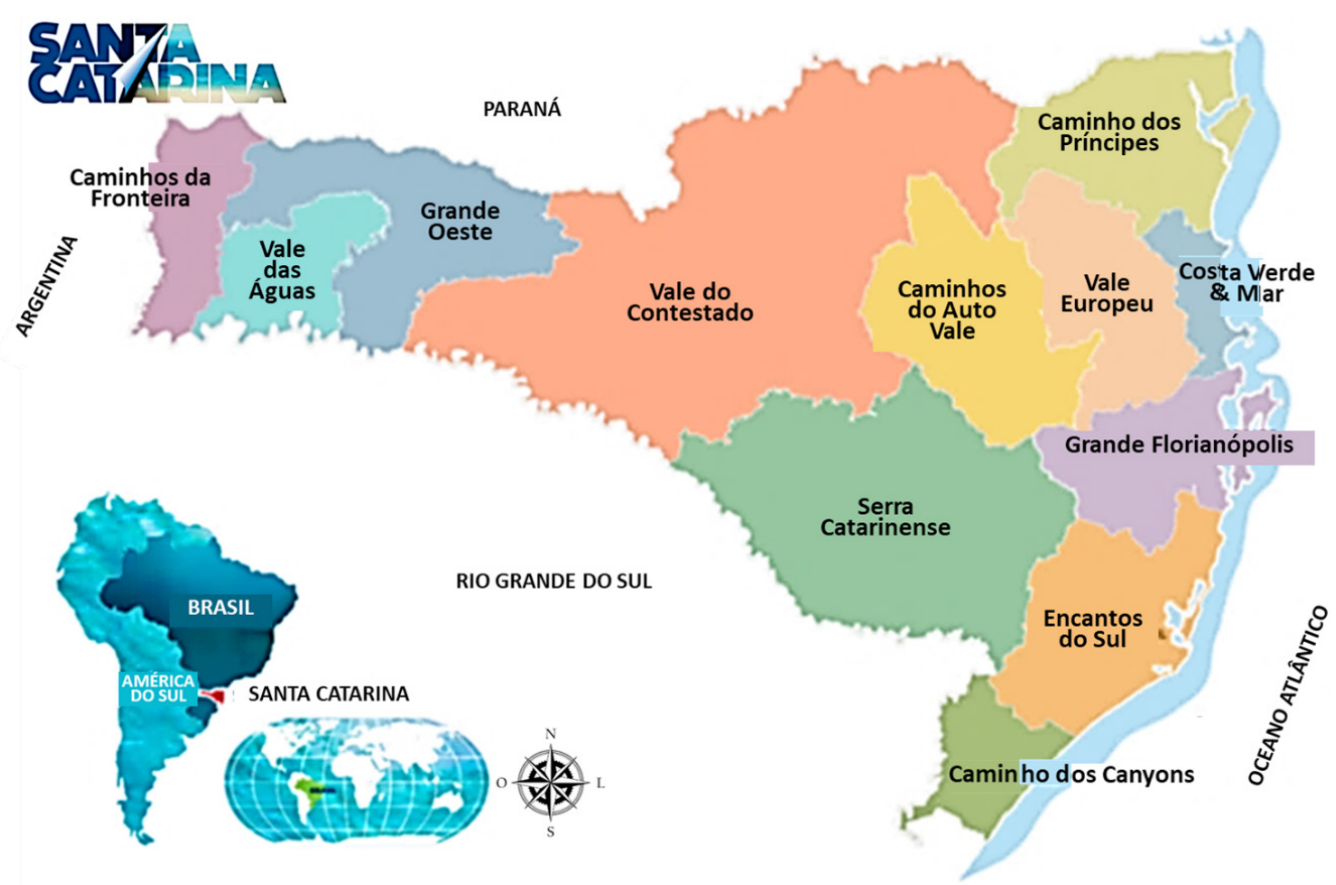

Como principais características do método de pesquisa survey podem ser citadas o interesse de produzir descrições quantitativas de uma população fazendo uso de um instrumento predefinido. Por se tratar de uma pesquisa de natureza aplicada a fim de se efetuar a coleta dos dados, o presente trabalho após pesquisa bibliográfica, foi estruturado em duas etapas.

Na primeira etapa, foi realizada a elaboração do questionário pelo método survey com adequações ao universo do guia de turismo e clientes. Na segunda etapa, uma nova aplicação foi realizada por se tratar de uma pesquisa quantitativa na busca de se obter os resultados finais por meio da tabulação dos dados para então, prosseguir com as análises estatísticas e interpretação dos mesmos.

Para a verificação da confiabilidade do questionário adaptado, foi realizado um pré-teste. A aplicação do questionário pré-teste com o Likert 5 , foi realizado em três entre janeiro e fevereiro de 2016 em roteiros pelo SESC-SC, Unidade Florianópolis - Prainha. Para tanto, o critério utilizado foi por meio do parâmetro Alpha de Cronbach (Tabela 1).

Tabela 1: Tabela dos valores para Alpha de Cronbach dos clientes e dos guias

\begin{tabular}{|l|l|l|l|l|} 
& Cliente Likert $\mathbf{5}$ & & Guia Likert $\mathbf{5}$ & \\
\hline Alpha de Cronbach & 0,96 & 0,81 &
\end{tabular}

Fonte: Resultados apurados da aplicação dos questionários (pré-teste) aos clientes e guias. 
Conforme resultados apurados, verifica-se que os questionários aplicados aos clientes e aos guias possuem uma consistência interna na sua elaboração, uma vez que os valores encontrados se aproximam de 1, que é o máximo da escala desse parâmetro.

Na segunda etapa entre outubro de 2016 a dezembro de 2016, com a confiabilidade do questionário comprovada, estes foram aplicados em nove viagens que contaram com 284 clientes (turistas/excursionistas), e nove guias de turismo. Para a definição do tamanho da amostra dos clientes, o cálculo foi realizado com base na fórmula de Barbetta (2002) para amostras probabilísticas simples, considerando um erro amostral tolerável de 5 pontos percentuais. A partir dos dados de 284 clientes e assumindo esse número como o total da população, a amostra mínima foi estimada em 164 participantes mínimos. Porém, este número foi superado alcançando uma amostra de 180 casos válidos. No caso dos guias, o levantamento foi realizado na sua totalidade.

\section{Procedimento de análise}

O tratamento nas respostas obtidas após a aplicação dos questionários foi realizado por meio de inferências estatísticas, procedimento necessário para avaliar a percepção dos clientes (turistas/excursionistas) quanto à qualidade da prestação dos serviços recebidos; e ponderar a percepção dos guias quanto ao serviço prestado, com o propósito de verificar e comparar a possível existência de diferença de médias das respostas entre as percepções do cliente e as percepções do guia de turismo nos 22 itens do questionário, bem como nas dimensões que compõem a qualidade em serviços e contemplar os objetivos da pesquisa.

A análise de dados foi realizada por meio do software Sphinx Plus2 (FREITAS; MOSCAROLA, 2000), o que possibilitou as inferências estatísticas. A diferença de médias foi analisada por meio do teste de Tukey.

\section{RESULTADOS}

Os resultados apresentados a seguir estão organizados conforme objetivos específicos propostos, refletindo a percepção dos clientes (turistas/excursionistas) quanto à qualidade da prestação dos serviços dos Guias de Turismo; a percepção dos Guias quanto à forma que eles acreditam que os clientes avaliam o serviço por eles prestado; e as possíveis lacunas (gaps) existentes na qualidade dos serviços, considerando as percepções do turista e do guia. Também se apresenta uma breve descrição do perfil da amostra.

\section{Perfil dos Clientes (turistas/excursionistas) e Guias de Turismo participantes do estudo}

No caso deste estudo, os dois grupos definidos para a pesquisa foram: 180 contratantes que usufruíram dos pacotes turísticos do SESC Florianópolis (Prainha), tratados neste estudo como clientes (turistas/excursionistas); e os Guias de 
Turismo que atenderam aos nove roteiros praticados. Em relação aos integrantes do primeiro grupo, as variáveis analisadas compreenderam: gênero, estado civil, faixa etária, nível de escolaridade, renda média mensal familiar, cidade e estado de residência e motivo da viagem.

Quanto às variáveis gênero, o público feminino foi predominante $(80,6 \%)$, com uma diferença considerável se comparado ao público masculino (19,4\%). Em relação à faixa etária e gênero, os dados identificaram que a maioria dos clientes se encontram na faixa etária entre 60 e 69 anos $(41,1 \%)$ e 70 anos ou mais $(25,6 \%)$, somando $66,7 \%$ do total, dos quais $51,5 \%$ são mulheres.

Em relação ao estado civil e gênero, dentre os 37,8\% respondentes casados, constata-se que $13,4 \%$ são mulheres casadas, viajando sozinhas. 0 percentual de viúvas é 18,2 vezes maior se comparado com o de viúvos, demonstrando que as mulheres possuem mais disponibilidade para viajar. No que diz respeito a escolaridade, $43 \%$ possuem formação superior completa, dentre os quais $10 \%$ são pós-graduados. Outros $33 \%$ possuem ensino médio completo. A renda média familiar concentra-se principalmente entre 1 a 3 (37,2\%) e 4 a 6 (31,7\%) salários mínimos, perfil este de acordo com o foco do Turismo Social aplicado pelo SESC. Predominantemente, residem em Florianópolis $(80,6 \%)$, sede do SESC Prainha, seguidos pelos 14,4\% que indicam como domicilio São José, ambos municípios do Estado de Santa Catarina, que ao todo corresponde a 98,9\% dos estados de residência dos entrevistados.

Os respondentes foram também questionados quanto aos motivos de viagem, com a opção de indicar mais de uma opção. A recreação foi o motivo mais citado, mencionado por $46 \%$ dos respondentes, seguido por conhecer novas pessoas (36\%), conhecer as programações do SESC (32\%) e aquisição e troca de conhecimento (31\%). Destaca-se que o motivo conhecer novos lugares não foi mencionado por nenhum dos respondentes, indicando o conhecimento anterior dos destinos visitados.

Quanto ao guia de turismo considerou-se as variáveis gênero; número de vezes que atuou pelo SESC; e o tempo de atuação na profissão. A aplicação dessas variáveis foi no intuito de mensurar e discutir questões pertinentes a respeito do perfil do profissional respondente. Referente as variáveis idade/gênero, constatou-se que os guias masculinos somaram $12 \%$ a mais nas atuações dos roteiros regionais do SESC - SC investigados, em relação ao percentual de atuação das guias femininas (44\%). As faixas etárias de maior concentração dos guias encontram-se entre 30 a 39 e 40 a 49 anos, ambos com 33\% cada do total dos guias.

No que diz respeito ao número de vezes em que o guia de turismo atuou nos roteiros regionais pelo SESC - SC, a análise apresenta que $89 \%$ atuaram em mais de 10 viagens, dentre os quais $22 \%$ com mais de 20 viagens, indicando experiência na atividade. Além disso, embora a classificação brasileira de ocupações (MTE - CBO, 2002), afirme que "o pleno desempenho das atividades dos guias de turismo ocorre após cinco anos de experiência", as análises demonstraram que $22,2 \%$ de guias apresentaram mais de dez anos de atuação. Os profissionais que atuam de um a três anos e de três a cinco anos, apresentaram uma regularidade de trabalho, somando $77,7 \%$ do percentual de frequência de guiamentos em relação ao total, demonstrando uma capacidade técnica de atendimento ao mercado de trabalho no turismo. 


\section{Avaliação da percepção dos clientes (turistas/excursionistas) quanto à qualidade da prestação dos serviços do Guia de Turismo}

A Tabela 2, apresenta a análise descritiva das médias em relação aos questionários aplicados aos 180 clientes em relação às 22 variáveis que contemplam o modelo SERVPERF. A importância das 22 variáveis foi mensurada por meio da Escala Likert 5 que atribuíram níveis de (1) discordo totalmente a (5) concordo totalmente. Essas variáveis estão relacionadas as dimensões do modelo em função do numérico. Assim, a dimensão Tangibilidade contempla os números de $\{1, \ldots, 4\}$; Confiabilidade $\{5, \ldots, 9\}$; Responsividade $\{10, \ldots, 13\}$; Segurança $\{14, \ldots, 17\}$ e Empatia $\{18, \ldots, 22\}$.

Considerando que as médias foram definidas com base no número de respondentes que avaliaram as variáveis, já que lhes era permitido também indicar as opções "não observado" (NO) e "não se aplica" (NSA), mesmo que os cálculos tenham sido realizados sem considerar as não respostas, estas somam o total de 2,3\% do conjunto das variáveis.

A análise da Tabela 2, mostra que a média geral do conjunto se encontra próximo ao escore 5, que é o máximo da escala desse parâmetro. Os valores médios máximos e mínimos estão nas variáveis cortesia 4,84 $\pm 0,48$ e equipamentos 4,18 $\pm 1,14$, os quais por sua vez pertencem as dimensões de segurança e tangibilidade respectivamente.

Tabela 2: Análise descritiva da avaliação da percepção dos clientes quanto à qualidade da prestação dos serviços do Guia de Turismo, em relação às 22 variáveis e as 5 dimensões

Fonte: Resultados apurados na pesquisa. Elaboração da autora (2016).

Legenda: Frequência percentual \%; (frequência)

De acordo com Parasuraman. Zeithaml e Berrv (1988). a dimensão da auali-

\begin{tabular}{|c|c|c|c|c|c|c|c|c|}
\hline & 1 & 2 & 3 & 4 & 5 & Valor médio & Desvio-padrão & TOTAL \\
\hline 1 - Equipamentos & $5,5 \%(9)$ & $0,6 \%(1)$ & $22,4 \%(37)$ & $13,3 \%(22)$ & $58,2 \%(96)$ & 4,18 & 1,14 & $100 \%(165)$ \\
\hline 2 - Instalações físicas & $0,6 \%(1)$ & $0,6 \%(1)$ & $14,6 \%(25)$ & $17,0 \%(29)$ & $67,3 \%(115)$ & 4,5 & 0,81 & $100 \%(171)$ \\
\hline 3 - Apresentação & $1,1 \%(2)$ & $0,0 \%(0)$ & $9,6 \%(17)$ & $12,4 \%(22)$ & $76,8 \%(136)$ & 4,64 & 0,75 & $100 \%(177)$ \\
\hline 4 - Folhetos e folders & $0,0 \%(0)$ & $1,8 \%(3)$ & $17,0 \%(28)$ & $12,7 \%(21)$ & $68,5 \%(113)$ & 4,48 & 0,84 & $100 \%(165)$ \\
\hline 5 - Horário e data & $1,1 \%(2)$ & $1,1 \%(2)$ & $10,1 \%(18)$ & $8,9 \%(16)$ & $78,8 \%(141)$ & 4,63 & 0,8 & $100 \%(179)$ \\
\hline 6 -Solucionar problemas & $0,0 \%(0)$ & $0,0 \%(0)$ & $9,1 \%(16)$ & $9,1 \%(16)$ & $81,8 \%(144)$ & 4,73 & 0,62 & $100 \%(176)$ \\
\hline 7 - Confiança & $0,0 \%(0)$ & $0,0 \%(0)$ & $7,8 \%(14)$ & $7,8 \%(14)$ & $84,4 \%(152)$ & 4,77 & 0,58 & $100 \%(180)$ \\
\hline 8 - Serviços & $0,0 \%(0)$ & $0,0 \%(0)$ & $9,4 \%(17)$ & $7,2 \%(13)$ & $83,3 \%(150)$ & 4,74 & 0,62 & $100 \%(180)$ \\
\hline 9 - Tarefas & $0,0 \%(0)$ & $0,6 \%(1)$ & $8,7 \%(15)$ & $8,1 \%(14)$ & $82,7 \%(143)$ & 4,73 & 0,64 & $100 \%(173)$ \\
\hline 10 - Informação & $0,0 \%(0)$ & $0,6 \%(1)$ & $5,6 \%(10)$ & $10,1 \%(18)$ & $83,7 \%(149)$ & 4,77 & 0,57 & $100 \%(178)$ \\
\hline 11 - Prontidão & $0,6 \%(1)$ & $0,6 \%(1)$ & $6,1 \%(11)$ & $8,9 \%(16)$ & $83,9 \%(151)$ & 4,75 & 0,64 & $100 \%(180)$ \\
\hline 12 - Disposição & $0,6 \%(1)$ & $0,0 \%(0)$ & $8,4 \%(15)$ & $7,8 \%(14)$ & $83,2 \%(149)$ & 4,73 & 0,66 & $100 \%(179)$ \\
\hline 13 - Disposição1 & $0,6 \%(1)$ & $1,7 \%(3)$ & $10,4 \%(18)$ & $10,4 \%(18)$ & $76,9 \%(133)$ & 4,61 & 0,79 & $100 \%(173)$ \\
\hline 14 - Confiança1 & $0,6 \%(1)$ & $0,6 \%(1)$ & $7,2 \%(13)$ & $7,8 \%(14)$ & $83,9 \%(151)$ & 4,74 & 0,66 & $100 \%(180)$ \\
\hline 15 - Segurança & $0,0 \%(0)$ & $0,6 \%(1)$ & $6,7 \%(12)$ & $6,1 \%(11)$ & $86,7 \%(156)$ & 4,79 & 0,58 & $100 \%(180)$ \\
\hline $16-$ Cortesia & $0,0 \%(0)$ & $0,0 \%(0)$ & $5,0 \%(9)$ & $5,6 \%(10)$ & $89,4 \%(160)$ & 4,84 & 0,48 & $100 \%(179)$ \\
\hline 17 - Formação e conhecimentos & $0,0 \%(0)$ & $0,0 \%(0)$ & $6,3 \%(11)$ & $11,4 \%(20)$ & $82,3 \%(144)$ & 4,76 & 0,56 & $100 \%(175)$ \\
\hline 18 - Atenção individual & $1,7 \%(3)$ & $0,0 \%(0)$ & $6,9 \%(12)$ & $7,5 \%(13)$ & $83,8 \%(145)$ & 4,72 & 0,74 & $100 \%(173)$ \\
\hline 19 - horários/momentos & $0,6 \%(1)$ & $0,6 \%(1)$ & $7,4 \%(13)$ & $9,7 \%(17)$ & $81,7 \%(143)$ & 4,71 & 0,68 & $100 \%(175)$ \\
\hline 20 - Atenção & $0,0 \%(0)$ & $0,0 \%(0)$ & $7,6 \%(13)$ & $8,8 \%(15)$ & $83,5 \%(142)$ & 4,76 & 0,58 & $100 \%(170)$ \\
\hline 21 - Compromisso & $0,0 \%(0)$ & $0,6 \%(1)$ & $8,4 \%(15)$ & $6,1 \%(11)$ & $84,9 \%(152)$ & 4,75 & 0,62 & $100 \%(179)$ \\
\hline 22 - Entendimento & $0,0 \%(0)$ & $0,6 \%(1)$ & $9,3 \%(16)$ & $8,7 \%(15)$ & $81,4 \%(140)$ & 4,71 & 0,66 & $100 \%(172)$ \\
\hline Conjunto & $0,6 \%(22)$ & $0,5 \%(18)$ & $9,2 \%(355)$ & $9,3 \%(359)$ & $80,5 \%(3105)$ & 4,69 & & $100 \%(3859)$ \\
\hline
\end{tabular}

dade mais relevante para o cliente é a confiabilidade; quando essa dimensão é inexistente, as avaliações das outras dimensões podem vir a perder o sentido. 
No caso do presente estudo, o fator do Alpha de Cronbach para essa dimensão é de 0,95, elevando a credibilidade da avaliação dessa variável, além de justificar o sentido da investigação das demais variáveis. Além disso, nota-se que todos os resultados das variáveis (Variáveis 6 a 9) desta dimensão superaram médias de 4,73 pontos.

Destacam-se as variáveis "folhetos e folders, equipamentos, e instalações físicas" as quais representam 21,6 \% desse total. Mesmo sendo um pequeno percentual em relação ao total de respondentes; vale considerar o resultado, pois essas variáveis estão concentradas dentro da dimensão da tangibilidade que se "refere à aparência de qualquer evidência física" (ZEITHAML; BITNER, 2003). É fundamental destacar que, com base em Parasuraman e Berry (1995, p. 205), "os serviços são dominados pelas qualidades da experiência, atributos que, significativamente, só podem ser avaliados depois da compra e durante o consumo - produção", distinguindo-se dos produtos físicos que permitem certo nível de interação antes da compra e do consumo. Além disso, a avaliação da qualidade do serviço por meio do turista por ser "notoriamente uma atividade experiencial e emocional, requer a inclusão de aspectos emocionais e comportamentais" (LEZANA; VASCONCELOS, 2014, p. 495).

Os resultados apresentados na Tabela 2 convergem com a avaliação geral do nível de satisfação com o desempenho alcançado pelo guia na viagem (Tabela 3), e da qualidade do serviço prestado pelo guia na respectiva viagem (Tabela 4). A análise da Tabela 3, mostra que a avaliação do desempenho do serviço prestado pelo guia de turismo (Gap 3), alcança níveis de satisfação e muita satisfação, somando $93 \%$ do total.

Tabela 3: Avaliação do nível de satisfação do cliente com o desempenho alcançado pelo guia de turismo

\begin{tabular}{|l|l|l|l|}
\hline $\begin{array}{l}\text { Avaliação do nível de satisfação com } \\
\text { desempenho alcançado/Gênero }\end{array}$ & Masculino \% & Feminino \% & Total \% \\
\hline Muito insatisfeito & 0,00 & 1,0 & 1,0 \\
\hline Insatisfeito & 1,0 & 1,0 & 2,0 \\
\hline Indiferente & 0,0 & 4,0 & 4,0 \\
\hline Satisfeito & 6,0 & 33,0 & 39,0 \\
\hline Muito satisfeito & 12,0 & 42,0 & 54,0 \\
\hline Total & 19,0 & 81,0 & \\
\hline
\end{tabular}

Fonte: Resultados apurados na pesquisa. Elaboração da autora (2016).

Em relação à avaliação do cliente quanto à qualidade do serviço prestado, a análise da Tabela 4 abaixo, mostra que a qualidade do serviço realizado pelo guia é muito boa e excelente, alcançando $78 \%$ do total das observações. No entanto, esse resultado é diferente para os clientes masculinos e femininos. Enquanto $89,4 \%$ dos homens indicam que a qualidade é muito boa e excelente, entre as mulheres a indicação de qualidade nestes níveis é indicada por 75,3\%.

Tabela 4: Avaliação do cliente quanto à qualidade do serviço prestado pelo guia de turismo 


\begin{tabular}{|l|l|l|l|}
\hline $\begin{array}{c}\text { Avaliação da qualidade do serviço } \\
\text { prestado/Gênero }\end{array}$ & Masculino \% & Feminino \% & \multicolumn{1}{|c|}{ Total \% } \\
\hline Ruim & 0,00 & 1,0 & 1,0 \\
\hline Satisfatório & 1,0 & 11,0 & 12,0 \\
\hline Boa & 1,0 & 7,0 & 8,0 \\
\hline Muito boa & 6,0 & 28,0 & 34,0 \\
\hline Excelente & 11,0 & 33,0 & 44,0 \\
\hline Total & 19,0 & 81,0 & \\
\hline
\end{tabular}

Fonte: Resultados apurados na pesquisa. Elaboração da autora (2016).

\section{Percepção do Guia de Turismo}

A Tabela 5, apresenta a análise descritiva das médias alcançadas em relação às 22 variáveis que contemplam o modelo SERVPERF (CRONIN; TAYLOR, 1992), obtidas após a aplicação dos questionários aos 09 guias de turismo. Essas variáveis estão relacionadas as dimensões do modelo em função do numérico. Assim, a dimensão Tangibilidade contempla os números de $\{1, \ldots, 4\}$; Confiabilidade $\{5, \ldots$, 9\}; Responsividade $\{10, \ldots, 13\}$, Segurança $\{14, \ldots, 17\}$ e Empatia $\{18, \ldots, 22\}$.

Tabela 5: Análise descritiva da avaliação da qualidade percebida pelos Guias de

Turismo quanto ao serviço prestado, em relação às 22 variáveis e as 5 dimensões

Fonte: Resultados apurados na pesquisa. Elaboração da autora (2016)

Legenda: Frequência percentual \%; (frequência)

\begin{tabular}{|c|c|c|c|c|c|c|c|c|}
\hline & 1 & 2 & 3 & 4 & 5 & Valor médio & Desvio-padrão & TOTAL \\
\hline 1 - Equipamentos & $0,5 \%(1)$ & $0,0 \%(0)$ & $0,5 \%(1)$ & $0,0 \%(0)$ & $3,3 \%(6)$ & 4,25 & 1,49 & $4,4 \%(8)$ \\
\hline 2 - Instalações físicas & $0,0 \%(0)$ & $0,0 \%(0)$ & $0,0 \%(0)$ & $1,1 \%(2)$ & $3,8 \%(7)$ & 4,78 & 0,44 & $4,9 \%(9)$ \\
\hline 3 - Apresentação & $0,0 \%(0)$ & $0,0 \%(0)$ & $0,0 \%(0)$ & $0,5 \%(1)$ & $4,4 \%(8)$ & 4,89 & 0,33 & $4,9 \%(9)$ \\
\hline 4 - Folhetos e folders & $0,0 \%(0)$ & $0,0 \%(0)$ & $0,0 \%(0)$ & $0,0 \%(0)$ & $3,8 \%(7)$ & 5 & 0 & $3,8 \%(7)$ \\
\hline 5 - Horário e data & $0,0 \%(0)$ & $0,0 \%(0)$ & $0,0 \%(0)$ & $0,0 \%(0)$ & $4,9 \%(9)$ & 5 & 0 & $4,9 \%(9)$ \\
\hline 6 - Solucionar problemas & $0,0 \%(0)$ & $0,0 \%(0)$ & $0,5 \%(1)$ & $0,0 \%(0)$ & $4,4 \%(8)$ & 4,78 & 0,67 & $4,9 \%(9)$ \\
\hline 7 - Confiança & $0,0 \%(0)$ & $0,0 \%(0)$ & $0,0 \%(0)$ & $0,0 \%(0)$ & $4,9 \%(9)$ & 5 & 0 & $4,9 \%(9)$ \\
\hline 8 - Serviços & $0,0 \%(0)$ & $0,0 \%(0)$ & $0,0 \%(0)$ & $0,5 \%(1)$ & $4,4 \%(8)$ & 4,89 & 0,33 & $4,9 \%(9)$ \\
\hline 9 - Tarefas & $0,0 \%(0)$ & $0,0 \%(0)$ & $0,0 \%(0)$ & $0,0 \%(0)$ & $4,9 \%(9)$ & 5 & 0 & $4,9 \%(9)$ \\
\hline 10 - Informação & $0,0 \%(0)$ & $0,0 \%(0)$ & $0,0 \%(0)$ & $0,0 \%(0)$ & $4,4 \%(8)$ & 5 & 0 & $4,4 \%(8)$ \\
\hline 11 - Prontidão & $0,0 \%(0)$ & $0,0 \%(0)$ & $0,0 \%(0)$ & $0,5 \%(1)$ & $4,4 \%(8)$ & 4,89 & 0,33 & $4,9 \%(9)$ \\
\hline 12 - Disposição & $0,0 \%(0)$ & $0,0 \%(0)$ & $0,0 \%(0)$ & $0,0 \%(0)$ & $4,9 \%(9)$ & 5 & 0 & $4,9 \%(9)$ \\
\hline 13 - Disposição1 & $0,0 \%(0)$ & $0,0 \%(0)$ & $0,5 \%(1)$ & $0,5 \%(1)$ & $3,3 \%(6)$ & 4,63 & 0,74 & $4,4 \%(8)$ \\
\hline 14 - Confiança1 & $0,0 \%(0)$ & $0,0 \%(0)$ & $0,0 \%(0)$ & $0,5 \%(1)$ & $4,4 \%(8)$ & 4,89 & 0,33 & $4,9 \%(9)$ \\
\hline 15 - Segurança & $0,0 \%(0)$ & $0,0 \%(0)$ & $0,0 \%(0)$ & $0,5 \%(1)$ & $4,4 \%(8)$ & 4,89 & 0,33 & $4,9 \%(9)$ \\
\hline $16-$ Cortesia & $0,0 \%(0)$ & $0,0 \%(0)$ & $0,0 \%(0)$ & $0,0 \%(0)$ & $4,9 \%(9)$ & 5 & 0 & $4,9 \%(9)$ \\
\hline 17 - Formação e conhecimentos & $0,0 \%(0)$ & $0,0 \%(0)$ & $0,0 \%(0)$ & $1,1 \%(2)$ & $3,8 \%(7)$ & 4,78 & 0,44 & $4,9 \%(9)$ \\
\hline 18 - Atenção individual & $0,0 \%(0)$ & $0,0 \%(0)$ & $0,5 \%(1)$ & $1,6 \%(3)$ & $1,6 \%(3)$ & 4,29 & 0,76 & $3,8 \%(7)$ \\
\hline 19 - horários/momentos & $0,0 \%(0)$ & $0,0 \%(0)$ & $0,5 \%(1)$ & $1,1 \%(2)$ & $2,2 \%(4)$ & 4,43 & 0,79 & $3,8 \%(7)$ \\
\hline 20 - Atenção & $0,0 \%(0)$ & $0,5 \%(1)$ & $1,1 \%(2)$ & $0,0 \%(0)$ & $1,6 \%(3)$ & 3,83 & 1,33 & $3,3 \%(6)$ \\
\hline 21 - Compromisso & $0,5 \%(1)$ & $0,0 \%(0)$ & $0,0 \%(0)$ & $0,5 \%(1)$ & $3,3 \%(6)$ & 4,38 & 1,41 & $4,4 \%(8)$ \\
\hline 22 - Entendimento & $0,0 \%(0)$ & $0,0 \%(0)$ & $0,0 \%(0)$ & $0,5 \%(1)$ & $3,3 \%(6)$ & 4,86 & 0,38 & $3,8 \%(7)$ \\
\hline Conjunto & $1,1 \%(2)$ & $0,5 \%(1)$ & $3,8 \%(7)$ & $9,3 \%(17)$ & $85,2 \%(156)$ & 4,77 & & $100 \%(183)$ \\
\hline
\end{tabular}

A análise da Tabela 5, mostra que os valores médios máximos estão nas variáveis de folhetos e folders, horário e data, confiança, serviços, tarefas, disposição e segurança com escore 5 . 0 valor mínimo está em Atenção, com valor médio de $3,83 \pm 1,33$, Equipamentos $(4,25 \pm 1,49)$ e Atenção Individual $(4,29 \pm 0,76)$. A 
média geral do conjunto está próximo de 5 indicando que o guia de turismo se sente confiante ao realizar o serviço.

A análise das Tabelas 6 e 7 abaixo, estão associados aos resultados da auto avaliação dos guias, o qual trata sobre as percepções dos gerentes (nesse caso os guias de turismo), em relação às expectativas e as especificações da qualidade do serviço prestado. Desse modo, a análise da Tabela 6, demonstra que a auto avaliação do desempenho do serviço prestado pelos guias de turismo posiciona a percepção em Satisfeito e Muito Satisfeito, que somados totalizam 100\% das indicações. Porém, quando analisados segundo o gênero, 40\% dos guias masculinos avaliam essa condição como Muito Satisfeito, enquanto os guias do gênero feminino alcançam apenas $25 \%$.

Tabela 6: Avaliação do nível de satisfação do guia de turismo em relação ao seu desempenho

\begin{tabular}{|l|l|l|l|}
\multicolumn{1}{|c|}{$\begin{array}{c}\text { Avaliação da satisfação do } \\
\text { desempenho/Gênero }\end{array}$} & Masculino \% & Feminino \% & \multicolumn{1}{c|}{ Total \% } \\
\hline 1) Muito insatisfeito & 0,00 & 0,00 & 0,00 \\
\hline 2) Insatisfeito & 0,00 & 0,00 & 0,00 \\
\hline 3) Indiferente & 0,00 & 0,00 & 0,00 \\
\hline 4) Satisfeito & 33,33 & 33,33 & 66,66 \\
\hline 5) Muito satisfeito & 22,22 & 11,11 & 33,33 \\
\hline Total & 55,55 & 44,44 & \\
\hline
\end{tabular}

Fonte: Resultados apurados da pesquisa. Elaboração da autora (2016).

Em relação à avaliação da qualidade do serviço, a análise da Tabela 7 demonstra que a auto avaliação do guia também alcança 100\% das indicações como boa e excelente. Porém, neste caso, $75 \%$ dos guias do gênero feminino o consideram como excelente, enquanto apenas $40 \%$ dos masculinos o indicam neste mesmo nível.

Tabela 7: Avaliação do guia de turismo quanto à qualidade do serviço prestado

\begin{tabular}{|l|l|l|}
\multicolumn{1}{|c|}{$\begin{array}{c}\text { Avaliação da satisfação do desempenho/ } \\
\text { Gênero }\end{array}$} & \multicolumn{1}{c|}{ Masculino \% } & Feminino \% \\
\hline 1) Ruim & 0,00 & 0,00 \\
\hline 2) Satisfatória & 0,00 & 0,00 \\
\hline 3) Boa & 0,00 & 0,00 \\
\hline 4) Muito Boa & 33,33 & 11,11 \\
\hline 5) Excelente & 22,22 & 33,33 \\
\hline TOTAL & 55,55 & 44,44 \\
\hline
\end{tabular}

Fonte: Resultados apurados Elaboração da autora (2016).

\section{Comparação das percepções dos clientes e dos Guias de Turismo}


De acordo com Zeithaml e Bitner (2003, p. 96), "a confiabilidade de um serviço é a capacidade de realizá-lo de forma confiável e preciso". A Tabela 8 demonstra essa situação na dimensão confiabilidade, pois indica que não existe diferença significativa entre o ponto de vista do guia (expectativa) e o serviço recebido pelos clientes (performance). Fazendo um comparativo da porcentagem entre a expectativa do serviço e a performance, conclui-se que em média a dimensão confiabilidade atendeu $95,66 \%$ do esperado.

Tabela 8: Teste de Tukey: duas amostras presumindo variâncias diferentes Dimensão Confiabilidade

\begin{tabular}{|l|l|l|}
\hline & \multicolumn{1}{|c|}{ Cliente } & \multicolumn{1}{c|}{ Guia } \\
\hline Média & 4,72 & 4,934 \\
\hline Variância & 0,0028 & 0,00968 \\
\hline Observações & 5 & 5 \\
\hline Hipótese da diferença de média & 0 & \\
\hline Gl & 6 & \\
\hline Stat t & $-4,28343$ \\
\hline P(T<=t) uni-caudal & 0,002593 & \\
\hline t crítico uni-caudal & 1,94318 & \\
\hline P(T<=t) bi-caudal & 0,005186 & \\
\hline t crítico bi-caudal & 2,446912 & \\
\hline
\end{tabular}

Fonte: Resultados apurados da pesquisa. Significância de 0, 05. Elaboração da autora (2016).

Apesar do resultado, faz se necessário um trabalho peculiar em conjunto entre a empresa e o seu funcionário (guia de turismo), afim de alcançar a excelência da aceitabilidade do serviço como é proposto nos trabalhos realizados por Bojanic e Rosen (1994) e Markovic et al. (2015), quando discutem as lacunas dos serviços prestados por meio de inferências estatísticas entre as dimensões. Buosi et al. (2012), concluíram também que a dimensão mais importante foi a confiabilidade, no entanto, a importância das dimensões demonstra uma relação direta com o setor que está sendo analisado, bem como o perfil dos clientes, necessitando considerar outras variáveis para a análise da satisfação.

Considerado os resultados deste estudo para a dimensão confiabilidade, com fator do Alpha de Cronbach de 0,95, a próxima análise (Tabela 9) refere-se ao teste de Tukey comparando a diferença de médias entre o cliente (performance) e o guia de turismo (expectativa) aplicado nas dimensões de tangibilidade, responsividade, segurança e empatia. 
Fonte: Resultados apurados da pesquisa. Significância de 0, 05. Elaboração da autora (2016).

Os resultados da Tabela 9 indicam que também não existe diferenca signi-

\begin{tabular}{lrrrrrrrrr}
\hline & \multicolumn{2}{c}{ Tangibilidade } & \multicolumn{2}{c}{ Responsividade } & \multicolumn{2}{c}{ Segurança } & & \multicolumn{2}{c}{ Empatia } \\
\hline & cliente & guia & cliente & guia & cliente & guia & cliente & guia \\
Média & 4,450 & 4,730 & 4,715 & 4,880 & 4,783 & 4,890 & 4,730 & 4,358 \\
Variância & 0,037 & 0,110 & 0,005 & 0,030 & 0,002 & 0,008 & 0,001 & 0,135 \\
Observações & 4,000 & 4,000 & 4,000 & 4,000 & 4,000 & 4,000 & 5,000 & 5,000 \\
Hipótese da diferença de média & 0,000 & & 0,000 & & 0,000 & & 0,000 & \\
gl & 5,000 & & 4,000 & & 4,000 & & 4,000 & \\
Stat t & $-1,456$ & & $-1,748$ & & $-2,154$ & & 2,257 & \\
P(T<=t) uni-caudal & 0,103 & & 0,078 & & 0,049 & & 0,043 \\
t crítico uni-caudal & 2,015 & & 2,132 & & 2,132 & & 2,132 \\
P(T<=t) bi-caudal & 0,205 & & 0,155 & & 0,097 & & 0,087 & \\
t crítico bi-caudal & 2,571 & & 2,776 & & 2,776 & & 2,776 \\
\hline
\end{tabular}

ficativa entre o ponto de vista do guia (expectativa) e o serviço recebido pelos clientes (performance/desempenho), na análise das dimensões tangibilidade, responsividade, segurança e empatia, já que a performance atingiu em média valores de $94,1 \%$; 96,62\%; 97,8\% e 108,54\% respectivamente para a expectativa em cada dimensão.

0 destaque é observado na dimensão empatia, no qual o serviço realizado pelo guia supera sua expectativa em $8,54 \%$. Nesse caso, é evidente o alto nível de capacitação dos guias de turismo em suas conduções, bem como a preocupação da empresa com os seus clientes, devido ao alto valor de aceitação do serviço por parte destes, sendo a expectativa correspondida em média 99,34\% entre as dimensões.

\section{CONSIDERAÇÕES FINAIS}

A formação profissional e o aperfeiçoamento contínuo são indispensáveis à qualidade da prestação de seus serviços para a satisfação e usufruto da experiência do cliente, devido as variáveis consideradas no trade turístico, além da crescente concorrência no mercado de trabalho, bem como a adoção e popularização de novas tecnologias de informação e comunicação

Dentre as implicações resultantes, as análises estatísticas, assim como o cruzamento entre as 22 variáveis dentre as 5 dimensões do modelo SERVPERF adaptado, possibilitaram um aprofundamento e uma avaliação do perfil do cliente do Turismo Social e o seu grau de satisfação em relação à qualidade percebida.

Quanto à qualidade da prestação dos serviços dos Guias de Turismo, foi possível avaliar e quantificar a percepção dos clientes por meio das análises estatísticas aplicadas aos dados gerados pelos clientes que responderam o questionário adaptado do modelo. Os resultados mostraram que as médias dos escores alcançados nas 5 dimensões estiveram entre 4,358 e 4,93; sendo essas muito próximas umas das outras e próximas do valor máximo de 5.

Foi possível ponderar e quantificar a percepção dos Guias quanto ao serviço prestado, por meio de inferências estatísticas, aplicadas aos dados gerados pelos Guias que responderam o questionário do modelo. Os resultados mostraram que as médias dos escores alcançados nas 5 dimensões estiveram entre 4,45 e 4,78, sendo essas muito próximas umas das outras e próximas do valor máximo de 5. Além disso, os resultados demonstraram que o guia de turismo é o gerente da 
atividade ao criar uma expectativa quanto ao serviço prestado e levar em consideração as percepções dos serviços pelos clientes.

Pode-se concluir que foi possível adaptar e validar o modelo SERVPERF usando a escala Likert 5 para o universo do guia de turismo e do cliente. 0 modelo ajustado e a sua aplicação nos roteiros regionais do Sesc- SC, demonstrou que não existe diferença significativa das médias dentre as dimensões no que tange a performance do serviço prestado e percebido pelo guia de turismo, assim como, avaliado pelas percepções dos turistas, pois ambos apresentaram resultados semelhantes, ou seja, sem diferenças estatísticas significantes. Isso revela que tanto a empresa quanto o guia, atendem as demandas dos clientes, os quais, demonstraram estarem satisfeitos com o desempenho do profissional.

As altas porcentagens da performance em relação ao serviço recebido, indicam a existência de um bom nível de formação e capacitação técnica do guia de turismo, bem como uma boa gestão do SESC por meio da oferta dos passeios e excursões.

Quanto as possíveis lacunas (gaps) existentes na qualidade dos serviços, considerando o serviço percebido pelo cliente e a atuação do guia, os resultados demonstraram a inexistência de lacunas. Assim, com base nas dimensões analisadas, pode-se concluir que tanto o guia quanto o cliente estão satisfeitos com o serviço ofertado e recebido.

Contudo, para melhor adequação do modelo, propõe-se para trabalhos futuros, a aplicação do mesmo modelo em outros SESC's do estado de Santa Catarina ou em outras unidades federativas do Brasil, com o intuito de aumentar a amostragem do guia de turismo, bem como a dos clientes. Além disso, a aplicação pode ser considerada em outros segmentos turísticos onde ocorre atuação do guia de turismo, que não somente no Turismo Social, no sentido de aumentar os resultados sobre o tema.

\section{REFERÊNCIAS}

Abítia. S. R. Panorama do Turismo Social no Mundo. In. Carvalho, C.L; Barbosa, L.G.M. (Orgs.)(2006) Discussões e propostas para o turismo no Brasil: Observatório de Inovação do Turismo. Rio de Janeiro: SENAC NACIONAL, 146-154.

Barbetta. P. A. (2002) Estatística aplicada às ciências sociais. Cap. 3. Editora UFSC, 5a Edição.

Beni, M. C. (2006) Análise estrutural do turismo. 11a ed. rev. e atualiz. São Paulo: Editora SENAC.

BITS. (1996) Bureau Internacional du Tourisme Social. Declaração de Montreal. [S.l.]. Disponível em: <http://www.oits-isto.org/oits/files/resources/14.pdf>. Acesso em: 20 abril 2016.

Bojanic, D.C.; Rosen, L. D. (1994). Measuring service quality in restaurants: an application of the SERVQUAL instrument. Hospitality Research Journal, vol. 18, no. 1, pp. 4-14.

Brasil. Ministério do Trabalho e Emprego. Classificação Brasileira de Ocupações 5114: Guias de turismo. Disponível em: <http://www.mtecbo.gov.br/cbosite/pages/pesquisas/ResultadoOcupacaoMovimentacao.jsf.>. Acesso em: 9 out 2015.

Brenner, E. L. (2013) Turismo: teorias e modelos. Goiânia: R\&F Editora. 
Buosi, J. C.; Moura, J. de; Giraldi, E.; Oliveira, M. M. B.de. (2013) A influência das dimensões da qualidade na satisfação dos consumidores de serviços de beleza. Produto \& Produção, vol. 14 n.1, p. 128-148, fev.

Camisón, C.; Cruz, S.; González, T. (2006) Gestión de la Calidad: conceptos, enfoques, modelos y sistemas. Madrid. Pearson Educación, S. A.

Canani, I.S.S. (1999) Guia de turismo: o mérito da profissão. Revista Turismo e Análise. v. 10, n. 1, p. 92-106. Disponível em: <http://www.revistas.usp.br/rta/article/download/63461/66206.>. Acesso em: 15 jul 2015.

Cano, L. Z.; Morejón, V. M. M.; Andrade, J. G. R.; Sandoval, E. C. (2012) Propuesta de un modelo para mejorar la competitividade en el servicio de los guías de turistas en la ciudad de Cancún, Q. Roo. Revista Internacional Administracion \& Finanzas. vol. 5. n 2.

Carman, J. M. (1990) Consumer perceptions of service quality: an assessment of the Servqual dimensions. Journal of Retailing, v 66, n. 1, p. 33-55.

Chang, R. C.; Mak, A. H. N.; Wong, K. K. F. (2010) Factors affecting the service quality of the tour guiding profession in Macau. International Journal of Tourism Research. 12, 205-218. (www.interscience.wiley.com) DOI: 10.1002/jtr.746 Disponível em: <http:// web.a.ebscohost.com/ehost/pdfviewer/pdfviewer?vid=20\&sid=fd0f9910-e3b7-486b-98c5-32e4532adb5e\%40sessionmgr4004\&hid=4104>. Acesso em: 26 set. 2015.

Churchill, G.A.; Surprenant, C. (1982) An investigation into the determinants of customer satisfaction. Journal of Marketing Research, nov 1982; 19, 000004; ABI/INFORMGlobal. Disponível em: <http://www.geocities.ws/matthew_lau2002/Downloads/Satisfaction_ churchill.pdf>. Acesso em: 20 ago.2016.

Cronin, J. J.; Taylor, S. A. (1992) Measuring service quality: a reexamination and extension. Journal of Marketing, v. 56, no 3, jul.,1992 p. 55-68. American Marketing Association Stable. Disponível em: <http://www.jstor.org/stable/1252296>. Acesso em:16 out. 2015.

El-Sharkawy, O.K. (2015) Evaluating tourist satisfaction in accordance to tour guides performance: heritage guided tours in Egypt. Tourismos, 10, 1, 81-99, 2015. ISSN: 17908418. Disponível em: <http://web.b.ebscohost.com/ehost/pdfviewer/pdfviewer?sid=b2288901-a777-4d75-9271-01bf9f841 f89\%40sessionmgr104\&vid=19\&hid=118> . Acesso em: 25 abr.2016.

Falcão, C. H. P. Turismo social: em busca de maior inclusão da sociedade. In. Carvalho, C.L; Bbarbosa, L.G.M. (Orgs.) (2006)Discussões e propostas para o turismo no Brasil: Observatório de Inovação do Turismo. Rio de Janeiro: SENAC NACIONAL, 127-145.

FREITAS, H. M. R. de; MOSCAROLA, J. Análise de dados quantitativos e qualitativos: casos aplicados. Porto Alegre: Sphinx: editora Sagra Luzzatto, 2000. 176p.: il. Disponível em: <http://www.sphinxbr.com.br>. e <http://www.adm.ufrgs.br/professores/hfreitas>. Acesso em: 16 nov. 2015.

FOWLER, P; WEERAKIT, N. Critical issues affecting the servisse quality in water base tourism operator: a case study of the marine leisure tour guide in Andaman cluster, Thailand. Review of Management Innovation \&Creativity. 6, 19, 37-50, 2013. ISSN: 19346727. Disponível em: <http://web.a.ebscohost.com/ehost/detail/detail?sid=b4427802-ebb3-424a-ad5f0a2706005730\%40sessionmgr4008\&vid=0\&hid=4107\&bdata=Jmxhbmc9cHQtYnImc210ZT1laG9zdC1saXZl\#AN=94260632\&db=bth>. Acesso em: 20 set. 2016.

FUJII, C. A. M.; CALARGE, F.A.; MIGUEL, P. A. C.; SALLES, J. A. A.; VANALLE, R. M. Avaliação da qualidade de serviços internos: uma revisão da literatura. XXX Encontro Nacional de Engenharia de Produção. Maturidade e desafios da engenharia de produção: competitividade das empresas, condições de trabalho, meio ambiente. São Carlos, SP, Brasil, 1-14, out. 2010. Disponível em:<http://www.abepro.org.br/biblioteca/enegep2010_tn_ stp_114_751_15188.pdf.>. Acesso em: 12 out. 2016. 
GONZÁLEZ, N. F; MARTÍNEZ, J. L. B. El guía de turismo y la conservación del patrimonio cultural. In: TURyDES Revista de Investigación en Turismo y Desarrollo Local. v. 3, n. 8 2010.

HOWARD, J. A.; SHETH, J. N. The Theory of Buyer Behavior. Journal of the American Statistical Association.January 1969, DOI: 10.2307/2284311 Disponível em:

$<$ https://www.researchgate.net/researcher/2032809572_John_A_Howard>. Acesso em 12 out. 2016.

LEZANA, Á. G.R.; VASCONCELOS, A. M. Teoria e prática na pesquisa sobre qualidade em serviçosturísticos em periódicosinternacionais: uma revisão deliteratura de 2002a 2012.Rev. Adm.,UFSM,SantaMaria,v.7,número3,p.486-505,dez.2014.DOI:10.5902/198346598045 Disponível em: <http://web.b.ebscohost.com/ehost/pdfviewer/pdfviewer?sid=1956e99a-d3f9-459d-b60ff23295e054a3\%40sessionmgr120\&vid=13\&hid=116>. Acesso em: 28 mar. 2016.

MARCHETTI, R.; PRADO, P.H. M. Um tour pelas medidas de satisfação do consumidor. ERA. v. 41 n. 4 out. /dez. 2001. 57 RAE - Revista de Administração de Empresas/FGV-EAESP, São Paulo, Brasil.

MARKOVIC, S.; KOMSIC, J.; DORČIĆ, J. Measuring service quality in Croatian restaurants: application of DINESERV scale. Disponível em: <https://www.researchgate.net/publication/287214214 >. Acesso em: 02 out.2016. DOI: 10.13140/RG.2.1.4392.7129

MOSSBERG, L. L. Tour leaders and their importance in charter tours. Tourism Management, Vol. 16, No. 6, 1995. Elsevier Science. Disponível em: <http://www.sciencedirect. com/science/article/pii/026151779500052P >. Acesso em: 30 set. 2016.

NASCIMENTO, A. O.; SILVA, L.F.; GRECHI, C.D.A atuação do guia de turismo em Mato Grosso do Sul (Brasil): diagnóstico, aspectos conceituais e perspectivas para o segmento. Revista Hospitalidade. São Paulo, v. XI, n. 1, p. 23-44, jun. 2014. Disponível em: <http:// www.revhosp.org/ojs/index.php/hospitalidade/article/view/535>. Acesso em: 21 fev. 2016.

OITS. Organização Internacional do Turismo. (2015, p.7). Disponível em: <http://www. oits-isto.org/oits/files/resources/551.pdf>. Acesso em: 24 abr. 2016.

OLIVER, R. L. A Cognitive model of the antecedents and consequences of satisfaction decisions. Journal of Marketing Research, v. 17, n. 4, November, p. 460-69, 1980.Disponível em: <https://lms.ctu.edu.vn/dokeos/courses/KT321/document/LUOC_KHAO_TAI_ LIEU/satisfaction_OLIVER_1980.PDF>. Acesso em 24 abr. 2016.

PALADINI, E. P. As bases históricas da gestão da qualidade: a abordagem clássica da administração e seu impacto na moderna gestão da qualidade. Gestão \& Produção, v.5, n.3, p. 168-186, dez. 1998. Disponível em: <http://www.scielo.br/pdf/gp/v5n3/a02v5n3. pdf>. Acesso em: 10 nov. 2016.

PARASURAMAN, A.; ZEITHAML, V. A.; BERRY, L. L. A conceptual model of service quality and its implications for future research. Journal of Marketing, v.49, p. 41 -45, 1985.

PARASURAMAN, A.; ZEITHAML, V. A.; BERRY, L. L. SERVQUAL: a multiple-item scale for measuring consumer perceptions of service quality. Journal of Marketing, v.64, p.12-40, 1988.

PARASURAMAN, A.; BERRY, L. L. Serviços de marketing: competindo através da qualidade. Tradução: Beatriz Sidou. 3a ed. São Paulo: Maltese, 1995. Série Negócios.

RABOTÍC, B. Professional tourist guiding: the importance of interpretation for tourist experiences. Tourism \& Hospitality Management, 2010. Conference Proceedings. Faculty of Tourism \& Hospitality in Opatija, Biennial International Congress. 01 jan.2010. p. 1157-1167. Disponível em: <web.b.ebscohost.com/ehost/pdfviewer?vid=3\&sid=f30b- 
4c8d-4794-4386-894f-256d24eabdde\%40sessionmgr102\&hid=110>. Acesso em: 16 abr.2015.

SALOMI, G. G. E.; MIGUEL, P. A. C. Aplicação de modelos de avaliação da qualidade em serviços para mensuração da satisfação de clientes internos em uma empresa do setor industrial. Encontro Nacional de Engenharia de Produção, XXII, Anais... ENEGEP. Curitiba, 2002. Disponível em: <http://www.abepro.org.br/biblioteca/ENEGEP2002_TR21_0205. pdf>. Acesso em 20 set. 2016.

SANTUR. Secretaria de turismo de Santa Catarina. Disponível em: <http://turismo.sc. gov.br/o-estado/ />. Acesso em: 22 set. 2016.

SARMENTO, J.; COSTA, M. J. A percepção da mudança: o centro histórico de Trancoso. In: SANTOS, N.; CUNHA, L. (Coord.). Trunfos de uma geografia activa: desenvolvimento local, ambiente, ordenamento e tecnologia. Imprensa da Universidade de Coimbra / Coimbra University Press, 1 nov. 2011 - 887p. Disponível em: <http://dx.doi.org/10.14195/978989-26-0244-8>. Acesso em: 15 out. 2016.

SESC. Serviço Social do Comércio. Modelo da atividade Turismo social. Módulo de Programação: Turismo emissivo. Serviço Social do Comércio. Departamento Nacional. Divisão de Planejamento e Desenvolvimento, 2007. Disponível em: <http://www.sesc.com.br/ wps/wcm/connect/b71ffb3fbfd7463fae1f108b398d916e/modelo_turismo.pdf?MO$\mathrm{D}=\mathrm{AJPERES} \& C A C H E I D=b 71 \mathrm{ffb} 3 \mathrm{f}-\mathrm{bfd7}-463 \mathrm{f}-\mathrm{ae} 1 \mathrm{f}-108 \mathrm{~b} 398 \mathrm{~d} 916 \mathrm{e}>$. Acesso em: 20 mai. 2016.

SESC. Serviço Social do Comércio. Cadernos SESC de cidadania. Turismo social. Ano 2 número 7. São Paulo: SESC - São Paulo, 2011. Disponível em: <https://www.sescsp.org.br/ files/edicao_revista/9e0e8cda-05f1-40848de07f1c014e779b.pdf>. Acesso em: 20 ago. 2016

SILVA, J. R. A. R. da. Qualidade: Estudo conceitual. (Monografia) Curso de Administração da UniCEUB. Faculdade Ciências Sociais Aplicadas - FASA - Centro Universitário de Brasília. nov. 2006.

SOL. Secretaria de Estado turismo, cultura e esporte de Santa Catarina. Disponível em: <http://www.sol.sc.gov.br/index.php/turismo/regionalizacao-do-turismo>. Acesso em: 21 jan. 2017.

SOL. Secretaria de Estado turismo, cultura e esporte de Santa Catarina Mapa do turismo de Santa Catarina ganha duas novas regiões. Disponível em: <http://www.sc.gov.br/ mais-sobre-turismo/21615-mapa-do-turismo-de-santa-catarina-ganha-duas-novas-regioes>. Acesso em: 22 set. 2016.

TÉBOUL, J. A era dos serviços: uma nova abordagem de gerenciamento. Rio de Janeiro: Qualitymark, 1999.

UNWTO. United Nations World Tourism Organization. Código Mundial de Ética do Turismo. Disponível em: <http://ethics.unwto.org/sites/all/files/docpdf/portugal.pdf>. Acesso em: 10 set. 2016.

WFTGA. World Federation of Tourist Guides Associations Guiding. An overview of the guiding profession with information on tourist guide associations, membership, the organization of tourist guides associations, qualifications required conditions of work, fees, and legal issues. Document Worldwide. January 2011. Disponível em: <http://wftga.org/sites/default/files/imceuploads/documents/Jane\%200rde\%20Document\%20 2011.pdf>. Acesso em: 10 out. 2015

ZEITHAML, V. A; BITNER, M. J. Marketing de serviços: a empresa com foco no cliente. Trad. Martin Albert Haag e Carlos Alberto Silveira Netto Soares. 2a ed. Porto Alegre: Bookman, 2003. 
Recebido em: 09/02/2017

Aprovado em: 07/07/2017

\section{ContribuiçÃo}

Maria Helena Alemany Soares: Definição do problema de pesquisa e objetivos;

DESENVOLVIMENTO DA PROPOSIÇÃO TEÓRICA; REALIZAÇÃO DA REVISÃO BIBLIOGRÁFICA E FUNDAMENTAÇÃO TEÓRICA; ESCOLHA DOS PROCEDIMENTOS METODOLÓGICOS; COLETA DE DADOS; ANÁLISE DE DADOS; ELABORAÇÃO DE TABELAS, GRÁFICOS E FIGURAS; REALIZAÇÃO DE CÁLCULOS E PROJEÇÕES; REVISÃo CRÍTICA DO MANUSCRITO; REDAÇÃO DO MANUSCRITO; ADEQUAÇÃO DO MANUSCRITO ÀS NORMAS DA RTA.

Carlos Marcelo Ardigó: Definição do problema de pesquisa e objetivos; desenvolvimento da proposição teórica; realização da revisão bibliográfica e fundamentação teórica; escolha dos procedimentos metodológicos; análise de dados; elaboração de tabelas, gráficos e figuras; realização de cálculos e projeções; revisão crítica do manuscrito; redação do manuscrito; adequação do manuscrito às normas da RTA.

Marcos Estevão Santiago de Melo Filho: Escolha dos procedimentos metodológicos; análise de dados; elaboração de tabelas, gráficos e figuras; realização de cálculos e projeções; revisão crítica do manuscrito. 